\title{
Impact of the indexed effective orifice area on mid-term cardiac-related mortality after aortic valve replacement
}

\author{
Sabine Bleiziffer, ${ }^{1}$ Ayyaz Ali, ${ }^{2}$ Ina M Hettich, ${ }^{1}$ Deniz Akdere, ${ }^{1}$ Rüdiger $\mathrm{P}$ Laubender, ${ }^{3}$ \\ Daniel Ruzicka, ${ }^{1}$ Johannes Boehm, ${ }^{1}$ Rüdiger Lange, ${ }^{1}$ Walter Eichinger ${ }^{1}$
}

${ }^{1}$ Clinic for Cardiovascular Surgery, German Heart Centre, Munich, Germany ${ }^{2}$ Stanford University Medical Center, California, USA ${ }^{3}$ Institute of Medical Informatics, Biometry and Epidemiology, LMU Munich, Munich, Germany

Correspondence to Dr Sabine Bleiziffer, Clinic for Cardiovascular Surgery, German Heart Centre Munich, Lazarettstr 36, 80636 Munich, Germany;

bleiziffer@dhm.mhn.de

Accepted 3 February 2010

\begin{abstract}
Background There has been ongoing controversy as to whether prosthesis-patient mismatch (PPM, defined as indexed effective orifice area (EOAl) $<0.85 \mathrm{~m}^{2} / \mathrm{cm}^{2}$ ) influences mortality after aortic valve replacement (AVR). In most studies, PPM is anticipated by reference tables based on mean EOAs as opposed to individual assessment. These reference values may not reflect the actual in vivo EOAl and hence, the presence or absence of PPM may be based on false assumptions.
\end{abstract}

Objective To assess the impact of small prosthesis EOA on survival after aortic valve replacement AVR.

Methods 645 patients had undergone an AVR between 2000 and 2007 entered the study. All patients underwent transthoracic echocardiography for determination of the actual EOAI within 6 months postoperatively. In order to predict time from surgery to death a proportional hazards model for competing risks (cardiac death vs death from other causes) was used. EOAl was entered as a continuous variable.

Results PPM occurred in $40 \%$ of the patients. After a median follow-up of 2.35 years, $92.1 \%$ of the patients were alive. The final Cox regression model showed a significantly increased risk for cardiac death among patients with a smaller EOAI $(H R=0.32, p=0.022)$. The effect of EOAI on the 2-5 year mortality risk was demonstrated by risk plots.

Conclusions In contrast to previous studies these EOAI values were obtained through postoperative echocardiography, substantially improving the accuracy of measurement, and the EOAI was modelled as a continuous variable. There was a significantly improved survival for larger EOAls following AVR. Strategies to avoid PPM should become paramount during AVR.

The concept of prosthesis-patient mismatch (PPM) was first introduced by Rahimtoola, ${ }^{1}$ and occurs when the effective orifice area of an aortic valve prosthesis is considered to be too small in relation to a patient's body size. ${ }^{2}$ PPM reflects residual aortic stenosis and, consequently, may lead to incomplete left ventricular mass regression and possibly decreased survival after aortic valve replacement (AVR). The majority of studies evaluating the impact of PPM on outcomes following AVR have relied on effective orifice area (EOA) estimations obtained from previously published reference tables. However, individual echocardiographic EOA measurements might more accurately account for interindividual variety in the EOA of patients. Furthermore, the EOA index (EOAI) has predominantly been studied as a categorical variable, whereas its analysis as a continuous variable is likely to be a more appropriate means of establishing its impact on morbidity and mortality following AVR. The aim of our study was to investigate the impact of EOAI on mid-term survival in patients undergoing AVR, analysing EOAI as a continuous rather than categorical variable.

\section{METHODS}

We analysed our outpatient clinic database and identified 645 patients who had undergone bioprosthetic primary AVR between July 2000 and January 2007, with at least 6 months of follow-up. These patients had undergone echocardiography for postoperative calculation of the EOAI. Between July 2007 and December 2007, follow-up data were collected from these patients using a questionnaire, and patient survival status was assessed by scrutinising hospital records. Baseline characteristics and operative data are summarised in table 1 with respect to an EOAI of $\geq 0.85 \mathrm{~cm}^{2} / \mathrm{m}^{2}$ or $<0.85 \mathrm{~cm}^{2} / \mathrm{m}^{2}$. All patients signed an informed consent form.

\section{Echocardiography}

Echocardiography was performed $6.5 \pm 1.5$ months postoperatively. All examinations were performed by a single dedicated and experienced echocardiographer. Echocardiography was carried out using an image Point Hx ultrasound system with a $2.5 \mathrm{MHz}$ transducer (Hewlett Packard, USA). Peak and mean systolic pressure gradients in the left ventricular outflow tract (LVOT) were measured $1 \mathrm{~cm}$ below the valve in an apical three- or five-chamber view. Pulsedwave Doppler was used for LVOT measurements and continuous-wave Doppler for the transvalvular measurements. In patients who were in sinus rhythm the three best available signals were averaged. If atrial fibrillation was present a minimum of five measurements was averaged.

EOA was obtained using the continuity equation. ${ }^{3}$ EOAI is the EOA indexed to body surface area, where body surface area is derived from the Dubois formula. ${ }^{4}$ For descriptive data, PPM was defined as present in patients with an EOAI $\leq 0.85 \mathrm{~cm}^{2} / \mathrm{m}^{2} .5-9$

Left ventricular mass (LVM) was obtained with the Penn-Cube formula. ${ }^{10}$ Data for LVM calculation were complete in 581 patients. A residual left ventricular hypertrophy (LVH) was defined as an indexed LVM of $>125 \mathrm{~g} / \mathrm{m}^{2}$. ${ }^{11}$

\section{Statistical analysis}

This is a retrospective review of a consecutive series of patients who underwent AVR with 
Table 1 Patient characteristics

\begin{tabular}{|c|c|c|c|}
\hline Characteristics & $\begin{array}{l}\text { EOAI } \geq 0.85 \mathrm{~cm}^{2} / \mathrm{m}^{2} \\
(\mathrm{n}=389)\end{array}$ & $\begin{array}{l}\text { EOAI }<0.85 \mathrm{~cm}^{2} / \mathrm{m}^{2} \\
(\mathrm{n}=256)\end{array}$ & p Value \\
\hline $\begin{array}{l}\text { Age at time of operation } \\
\text { (years), mean } \pm S D\end{array}$ & $72.3 \pm 7.5$ & $72.3 \pm 7.9$ & 0.946 \\
\hline $\begin{array}{l}\text { Body surface area }\left(\mathrm{m}^{2}\right) \text {, } \\
\text { mean } \pm S D\end{array}$ & $1.85 \pm 0.18$ & $1.86 \pm 0.19$ & 0.320 \\
\hline $\begin{array}{l}\text { Body mass index } \\
\text { mean } \pm S D\end{array}$ & $26.6 \pm 3.8$ & $27.4 \pm 4.2$ & 0.011 \\
\hline Gender, female & $150(38.6)$ & $131(51.2)$ & 0.002 \\
\hline COPD & $54(13.9)$ & $34(13.3)$ & 0.818 \\
\hline Coronary heart disease & $199(51.3)$ & $141(55.1)$ & 0.346 \\
\hline Diabetes mellitus & $81(20.9)$ & $78(30.5)$ & 0.006 \\
\hline Hyperlipidaemia & $261(67.3)$ & $170(66.4)$ & 0.820 \\
\hline Nicotine abuse & $105(27.1)$ & $59(23.1)$ & 0.264 \\
\hline Arterial hypertension & $314(80.7)$ & $209(81.6)$ & 0.770 \\
\hline $\begin{array}{l}\text { Previous myocardial } \\
\text { infarction }\end{array}$ & $23(6.0)$ & $14(5.5)$ & 0.794 \\
\hline Previous cardiac surgery & $22(5.7)$ & $19(7.4)$ & 0.382 \\
\hline Peripheral vessel disease & $10(2.6)$ & $12(4.7)$ & 0.153 \\
\hline Carotid stenosis & $26(6.7)$ & $19(7.4)$ & 0.739 \\
\hline Liver disease & $7(1.8)$ & $4(1.6)$ & 0.810 \\
\hline Gastrointestinal disease & $18(4.7)$ & $17(6.6)$ & 0.280 \\
\hline Malignant tumour & $22(5.7)$ & $24(9.4)$ & 0.077 \\
\hline Renal insufficiency & $26(6.7)$ & $19(7.4)$ & 0.739 \\
\hline Coagulopathy & $2(0.5)$ & $2(0.8)$ & 0.678 \\
\hline Psychiatric disease & 0 & $1(0.4)$ & 0.219 \\
\hline Atrial fibrillation & $50(13.0)$ & $37(14.5)$ & 0.587 \\
\hline Residual LVH & $196 / 354(55)$ & $145 / 227(64)$ & 0.042 \\
\hline $\begin{array}{l}\text { Impaired left ventricular } \\
\text { function }\end{array}$ & & & 0.798 \\
\hline $\begin{array}{l}\text { Ejection fraction } \\
35-50 \%\end{array}$ & $70(18.2)$ & 47 (18.4) & \\
\hline $\begin{array}{l}\text { Ejection fraction } \\
<35 \%\end{array}$ & $14(3.6)$ & $12(4.7)$ & \\
\hline Concomitant procedure & $211(54.4)$ & $141(55.3)$ & 0.820 \\
\hline Implanted valve type & & & 0.006 \\
\hline CE Perimount* & $156(40.1)$ & $101(39.5)$ & \\
\hline Perimount Magna* & $56(14.4)$ & $56(21.9)$ & \\
\hline Medtronic Mosaic $†$ & $23(5.9)$ & $22(8.6)$ & \\
\hline Sorin Mitroflowł & $33(8.5)$ & $23(9.0)$ & \\
\hline SJM Epic Supra§ & $30(7.7)$ & $23(9.0)$ & \\
\hline Sorin Soloł & $13(3.3)$ & $7(2.7)$ & \\
\hline Soprano $\ddagger$ & $43(11.1)$ & $17(6.6)$ & \\
\hline Toronto Root§ & $35(9.0)$ & $7(2.7)$ & \\
\hline
\end{tabular}

Results are shown as number (\%) unless stated otherwise.

*Edwards Lifesciences (Irvine, California, USA):

† Medtronic (Minneapolis, Minnesota, USA);

$\neq$ Sorin Biomedica (Saluggia, Italy);

$\S$ St Jude Medical (St Paul, Minnesota, USA).

बResidual left ventricular hypertrophy was defined as an indexed left ventricular mass $>125 \mathrm{~g} / \mathrm{m}^{2} .11$

COPD, chronic obstructive pulmonary disease; LVH, left ventricular hypertrophy.

a bioprosthesis. Data are expressed as mean values \pm standard deviation for continuous variables, and as percentages for categorical variables. We considered time from operation to death as clinical end point. As cardiac death was the event of interest, we treated death due to other (non-cardiac) causes as possible competing risk. Therefore, we used techniques for analysing survival in a competing risk setting-namely, cumulative incidence functions for estimating the probability of the interesting events, Gray's test ${ }^{12}$ for comparing groups, and for multivariate modelling purposes the proportional hazards model for competing risks proposed by Fine and Gray. ${ }^{13}$ For modelling competing risks, we used complete cases with regard to the cause of death and the covariates of EOAI, age at time of operation, gender, arterial hypertension, chronic obstructive pulmonary disease, nicotine abuse, diabetes mellitus, coronary heart disease, preoperative ejection fraction, hyperlipidaemia, previous myocardial infarction, previous cardiac surgery, peripheral vessel disease, carotid stenosis, liver disease, gastrointestinal disease, malignant tumour, renal insufficiency, coagulopathy, psychiatric disease, atrial fibrillation and concomitant procedures. Using the proportional hazards model for competing risks, we developed a multivariate prognostic model which contains all the above-mentioned covariates statistically significant in the bivariate models at the $10 \%$ level. Further, the model fit (proportional hazards assumption, influential observations) of the resulting multivariate proportional hazards model was assessed by adequate diagnostic tools. Finally, we performed a sensitivity analysis for the subgroup of patients with a body mass index (BMI) of $\leq 30 \mathrm{~kg} / \mathrm{m}^{2}$. All calculations were performed in SPSS (SPSS 16.0) and R (version 2.9.2).

\section{RESULTS}

\section{Effective orifice area measurements}

The mean EOAs obtained echocardiographically for each valve size and type are summarised in table 2 .

By anticipating the presence or absence of PPM (defined as EOAI $<0.85 \mathrm{~cm}^{2} / \mathrm{m}^{2}$ ) with EOA charts containing the greatest amount of published data, ${ }^{14} 92$ patients (14.3\%) would have been correctly identified as presenting a PPM, 347 patients $(53.9 \%)$ would have correctly been identified as not presenting a PPM, and 42 (6.5\%) and $163(25.3 \%)$, respectively, would have had a false-positive and false-negative prediction, respectively.

Figure 1 further demonstrates that the EOA is not a constant predictable value by showing the EOA measurement distribution in $n=113$ patients who had had implanted the same valve type and size. The EOA measurements ranged from $0.88 \mathrm{~cm}^{2}$ to $3.49 \mathrm{~cm}^{2}$ with a mean value of $1.82 \mathrm{~cm}^{2}$ and a SD of $0.413 \mathrm{~cm}^{2}$.

\section{Survival analysis with competing risks using categorised EOAI}

We collected data of 645 patients of whom 630 patients had information on all covariates $(97.7 \%$ of all patients). A total of 51 events occurred during the follow-up period. Eight patients who died from unknown cause were excluded as they can be assumed to be missing completely at random. This led to a total of 622 patients with 43 events. We observed 25 cardiac deaths and 18 non-cardiac deaths.

As categorisation of the EOAI with a cut-off value of $0.85 \mathrm{~cm}^{2} / \mathrm{m}^{2}$ is commonly employed, we present our categorised data here to allow for improved comparison with other studies. The incidence of PPM $\left(\mathrm{EOAI}<0.85 \mathrm{~cm}^{2} / \mathrm{m}^{2}\right)$ in the study population was $39.9 \%(248 / 622)$

Mean and median follow-up time was 2.66 years and 2.35 years, respectively, with a range from 0.45 to 7.19 years. Cumulative incidence of cardiac death 1 year and 5 years after AVR was $0.8 \%$ (95\% CI $0.0 \%$ to $1.8 \%)$ and $5.4 \%(0.5 \%$ to $10.2 \%)$ in patients without PPM versus $2.6 \%(0.5 \%$ to $4.6 \%)$ and $10.4 \%$ (3.9\% to $16.8 \%$ ) in patients with PPM (Gray's test, $\mathrm{p}=0.11$, see figure 2). Cumulative incidence of non-cardiac death 1 and 5 years after AVR was $0.0 \%$ (no events observed) and $4.7 \%(1.3 \%$ to $8.1 \%)$ in patients without PPM versus $0.4 \%(0.0 \%$ to $1.3 \%)$ and $5.6 \%(0.9 \%$ to $10.3 \%)$ in patients with PPM (Gray's test, $\mathrm{p}=0.68)$.

Subgroup analysis of non-obese (BMI $<30 \mathrm{~kg} / \mathrm{m}^{2}$ ) patients (487 patients with 21 cardiac deaths and 12 non-cardiac deaths) revealed cumulative incidences for cardiac death of $1.0 \%(0.0 \%$ to $2.2 \%)$ and $6.9 \%(0.6 \%$ to $13.2 \%)$ after 1 and 5 years in patients without PPM versus $2.3 \%(0.1 \%$ to $4.5 \%)$ and $12.6 \%(4.3 \%$ to $21.0 \%$ ) in patients with PPM (Gray's test, $\mathrm{p}=0.19$, see figure 2 ). 
Table 2 Mean values and ranges of effective orifices areas measured at 6-month follow-up, according to the models and sizes of prostheses

\begin{tabular}{|c|c|c|c|c|c|c|}
\hline \multirow[b]{2}{*}{ Prosthesis } & \multicolumn{6}{|c|}{ Labelled valve size } \\
\hline & $\# 19$ & \#21 & \#23 & \#25 & \#27 & \#29 \\
\hline Edwards Perimount* & $\begin{array}{l}1.19 \\
(0.9 \text { to } \\
1.4) \\
n=11\end{array}$ & $\begin{array}{l}1.44 \\
(1.4 \text { to } \\
1.5) \\
n=7\end{array}$ & $\begin{array}{l}1.82 \\
(1.7 \text { to } \\
1.9) \\
\mathrm{n}=113\end{array}$ & $\begin{array}{l}1.90 \\
(1.8 \text { to } \\
2.0) \\
n=55\end{array}$ & $\begin{array}{l}2.38 \\
(1.5 \text { to } \\
3.2) \\
\mathrm{n}=4\end{array}$ & $\begin{array}{l}2.72 \\
(2.6 \text { to } \\
2.9) \\
n=2\end{array}$ \\
\hline $\begin{array}{l}\text { Edwards Perimount } \\
\text { Magna* }^{*}\end{array}$ & $\begin{array}{l}1.14 \\
(1.0 \text { to } \\
1.3) \\
n=10\end{array}$ & $\begin{array}{l}1.47 \\
(1.4 \text { to } \\
1.6) \\
n=47\end{array}$ & $\begin{array}{l}1.82 \\
(1.7 \text { to } \\
2.0) \\
\mathrm{n}=38\end{array}$ & $\begin{array}{l}2.01 \\
(1.8 \text { to } \\
2.2) \\
n=17\end{array}$ & & \\
\hline Medtronic Mosaic $\ddagger$ & $\begin{array}{l}0.53 \\
n=1\end{array}$ & $\begin{array}{l}1.11 \\
(0.9 \text { to } \\
1.3) \\
n=9\end{array}$ & $\begin{array}{l}1.53 \\
(1.3 \text { to } \\
1.8) \\
n=23\end{array}$ & $\begin{array}{l}1.94 \\
(1.6 \text { to } \\
2.2) \\
\mathrm{n}=10\end{array}$ & $\begin{array}{l}2.14 \\
(1.6 \text { to } \\
2.7) \\
n=2\end{array}$ & \\
\hline Sorin Mitroflow§ & $\begin{array}{l}0.92 \\
n=1\end{array}$ & $\begin{array}{l}1.43 \\
(1.3 \text { to } \\
1.6) \\
\mathrm{n}=20\end{array}$ & $\begin{array}{l}1.53 \\
(1.4 \text { to } \\
1.7) \\
n=19\end{array}$ & $\begin{array}{l}1.96 \\
(1.8 \text { to } \\
2.1) \\
n=12\end{array}$ & $\begin{array}{l}2.34 \\
(1.7 \text { to } \\
3.0) \\
n=4\end{array}$ & \\
\hline Sorin Freedom Solo§ & $\begin{array}{l}1.29 \\
n=1\end{array}$ & $\begin{array}{l}1.61 \\
(1.2 \text { to } \\
2.1) \\
n=3\end{array}$ & $\begin{array}{l}2.00 \\
(1.6 \text { to } \\
2.3) \\
n=7\end{array}$ & $\begin{array}{l}1.92 \\
(1.3 \text { to } \\
2.6) \\
n=5\end{array}$ & $\begin{array}{l}2.42 \\
(1.9 \text { to } \\
3.0) \\
n=4\end{array}$ & \\
\hline St Jude Epic Supra† & & $\begin{array}{l}1.46 \\
(1.4 \text { to } \\
1.8) \\
n=18\end{array}$ & $\begin{array}{l}1.81 \\
(1.6 \text { to } \\
2.0) \\
n=35\end{array}$ & & & \\
\hline \multirow[t]{3}{*}{ St Jude Toronto Root $†$} & & $\begin{array}{l}0.93 \\
n=1\end{array}$ & $\begin{array}{l}1.60 \\
(1.4 \text { to } \\
1.8) \\
n=6\end{array}$ & $\begin{array}{l}1.94 \\
(1.7 \text { to } \\
2.2) \\
n=16\end{array}$ & $\begin{array}{l}2.34 \\
(2.1 \text { to } \\
2.6) \\
n=11\end{array}$ & $\begin{array}{l}2.11 \\
(1.7 \text { to } \\
2.5) \\
n=8\end{array}$ \\
\hline & \multicolumn{6}{|c|}{ Labelled valve size } \\
\hline & \#18 & $\# 20$ & \#22 & \#24 & $\# 26$ & $\# 28$ \\
\hline Sorin Soprano§ & $\begin{array}{l}1.25 \\
(0.9 \text { to } \\
1.7) \\
n=3\end{array}$ & $\begin{array}{l}1.57 \\
(1.4 \text { to } \\
1.7) \\
n=15\end{array}$ & $\begin{array}{l}1.78 \\
(1.7 \text { to } \\
1.9) \\
n=20\end{array}$ & $\begin{array}{l}2.08 \\
(1.8 \text { to } \\
2.3) \\
n=18\end{array}$ & $\begin{array}{l}2.51 \\
(2.1 \text { to } \\
2.6) \\
\mathrm{n}=3\end{array}$ & $\begin{array}{l}2.40 \\
n=1\end{array}$ \\
\hline
\end{tabular}

The numbers in brackets indicate the $95 \% \mathrm{Cl}$.

*Edwards Lifesciences (Irvine, California, USA)

†St Jude Medical (St Paul, Minnesota, USA);

$\neq$ Medtronic (Minneapolis, Minnesota, USA);

$\S$ Sorin Biomedica (Saluggia, Italy).

A residual LVH of $>125 \mathrm{~g} / \mathrm{m}^{211}$ occurred significantly more often in patients with PPM $(145 / 227,64 \%)$ than in patients without PPM $(196 / 354,55 \%, \mathrm{p}=0.042)$ at 6 months after AVR. The cumulative incidence of cardiac death was increased in patients with residual LVH $(2.3 \%(0.7 \%$ to $3.8 \%)$ and $10.1 \%$

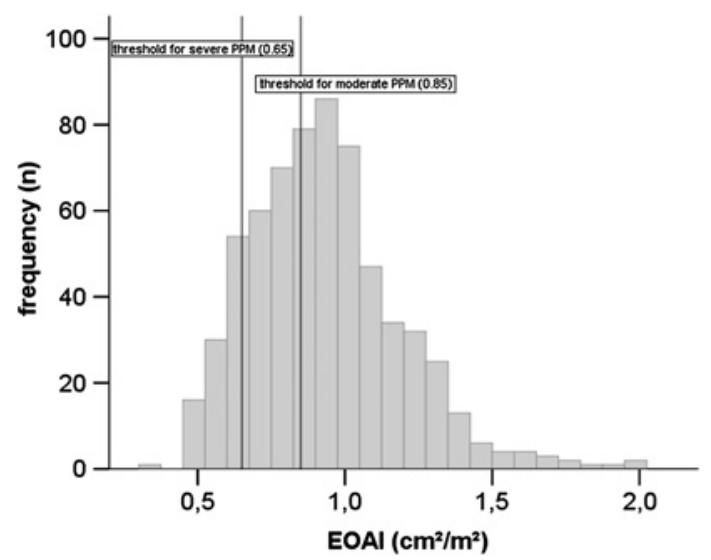

Figure 1 Variety of the effective orifice area of one prosthesis type and size. Histogram of the distribution of the effective orifice area (EOA) in 113 patients who had a prosthesis of the same type and size (Edwards Perimount size 23) implanted. The mean value of $1.82 \mathrm{~cm}^{2}$ would be the only character incorporated into a reference table. PPM, prosthesis-patient mismatch.
$(3.9 \%$ to $16.3 \%)$ at 1 and 5 years versus $0.5 \%(0.0 \%$ to $1.5 \%)$ and $4.4 \%(0.0$ to $8.9 \%)$ in patients with no residual $\mathrm{LVH}, \mathrm{p}=0.16)$. Among patients with residual LVH, those with PPM exhibit a higher cardiac mortality of $4.1 \%(0.6 \%$ to $7.6 \%)$ and $16.4 \%$ (4.0\% to $28.8 \%$ ) at 1 and 5 years, compared with patients with residual LVH but no PPM (1.3\% (0.0\% to $2.9 \%)$ and $5.9 \%(0.4 \%$ to $11.3 \%$ ) and Gray's test with $\mathrm{p}=0.07$, see figure 2 ).

\section{Multivariate survival analysis with competing risks using EOAI as a continuous parameter}

For the purpose of multivariate modelling, we did not categorise EOAI to avoid loss of power and other statistical problems. ${ }^{15}$ The histogram in figure 3 shows the distribution of EOAI in our patient cohort. As the distribution of EOAI is right skewed we logarithmically transformed the EOAI to get a more normally distributed covariate. The bivariate proportional hazards regression for competing risks (cardiac death as interesting event and non-cardiac death as competing risk) revealed logarithmic EOAI $(p=0.068)$, diabetes mellitus $(p=0.0015)$, preoperative ejection fraction $(E F)<50 \%(p=0.0022)$ and age at operation $(p=0.00011)$ as statistically significant predictors for cardiac death at the $10 \%$ level. These predictors entered simultaneously the multivariate proportional hazards regression model for competing risks (table 3 ). Regression diagnostics did not reveal any violated assumptions of the proportional hazards regression model for competing risks. The hazard ratios are given in table 3

\section{Sensitivity analysis in non-obese patients}

Adjusted for the predictors age, diabetes mellitus and preoperative $\mathrm{EF}<50 \%$, the HR for logarithmic EOAI is 0.31 and statistically significant $(p=0.021)$ (table 4 ).

\section{Risk plots}

Risk plots for four selected patient profiles were developed to illustrate the impact of the EOAI on cardiac death (figure 4). The risk plots indicate the cumulative incidence for cardiac death after 2, 3, 4 and 5 years in relation to EOAI

\section{DISCUSSION}

Although the concept of 'prosthesis-patient mismatch' was introduced almost 30 years ago, there remains no consensus about its impact on clinical outcome. Furthermore, there remains no standardised and universally accepted method for the calculation of PPM.

After weighing the pros and cons, our group considers echo measurements the most accurate method to assess the impact of the EOAI on mortality as opposed to anticipation of EOA. The key method of our study was to incorporate the EOAI as a continuous variable. The final multivariate model demonstrated a significantly increased risk for cardiac death with smaller EOAI after AVR, while the descriptive analysis using categorised EOAI did not reach statistical significance. The effect of EOAI on survival was only significant in the non-obese patients with a $\mathrm{BMI}<30 \mathrm{~kg} / \mathrm{m}^{2}$, and the cumulative incidence of cardiac death was strongly increased in patients with residual LVH and PPM.

\section{Suitability of EOA measurements}

In a previous investigation undertaken by our group, we demonstrated that EOA estimation from reference charts tabulated using data derived from large-scale echocardiography studies had a sensitivity of $71 \%$ and a specificity of $67 \%$, a positive predictive value of $64 \%$, and a negative predictive value of $74 \%{ }^{14}$ for the anticipation of PPM. These study data 

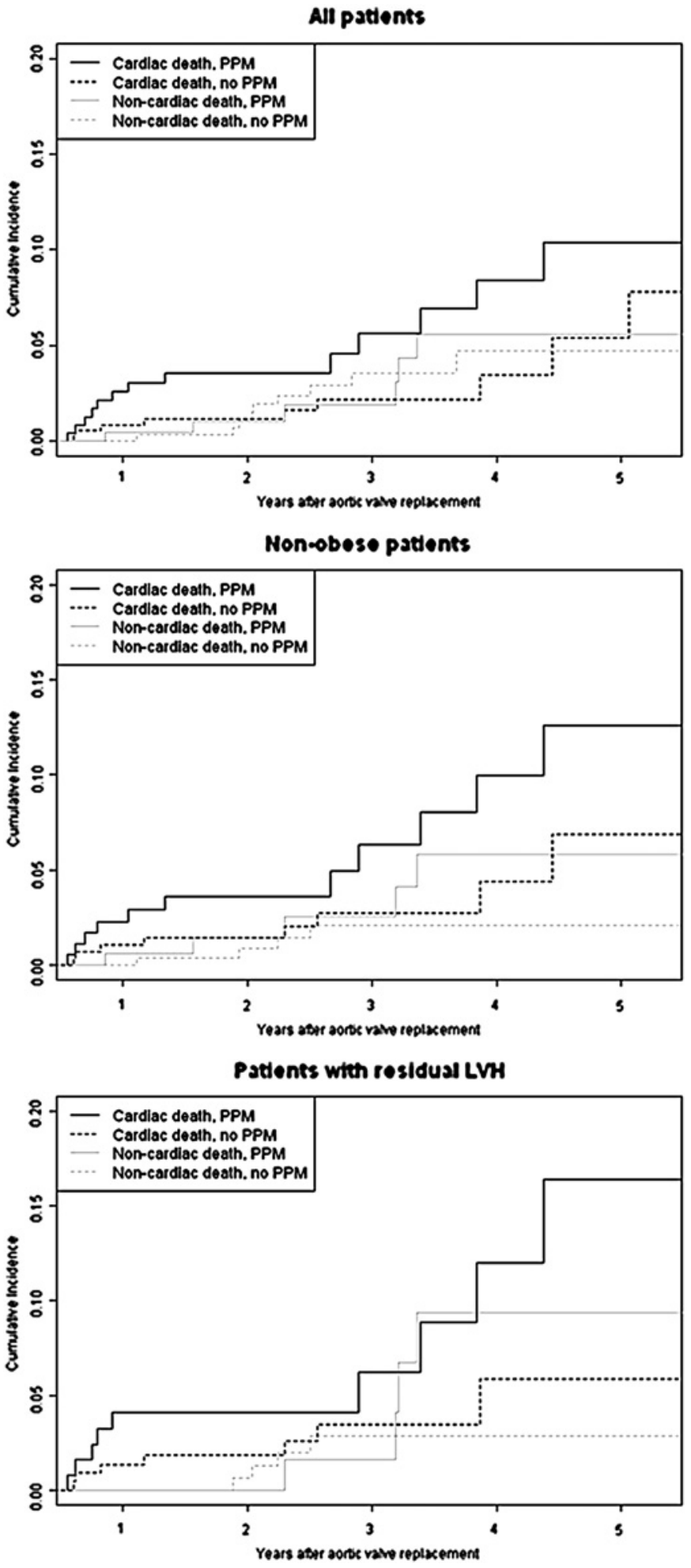

Figure 2 Cumulative incidence of death after aortic valve replacement. Top: cumulative incidence of death in the study population $(n=622$ patients). Middle: cumulative incidence of death in 487 non-obese patients (body mass index $<30 \mathrm{~kg} / \mathrm{m}^{2}$ ). Bottom: cumulative incidence of death in 341 patients with residual left ventricular hypertrophy. Solid black line: cardiac death in patients with prosthesis - patient mismatch (PPM), effective orifice area index $<0.85 \mathrm{~cm}^{2} / \mathrm{m}^{2}$ ); dotted black line: cardiac death in patients without PPM; solid gray line: non-cardiac death in patients with PPM; dotted gray line: non-cardiac death in patients without PPM.

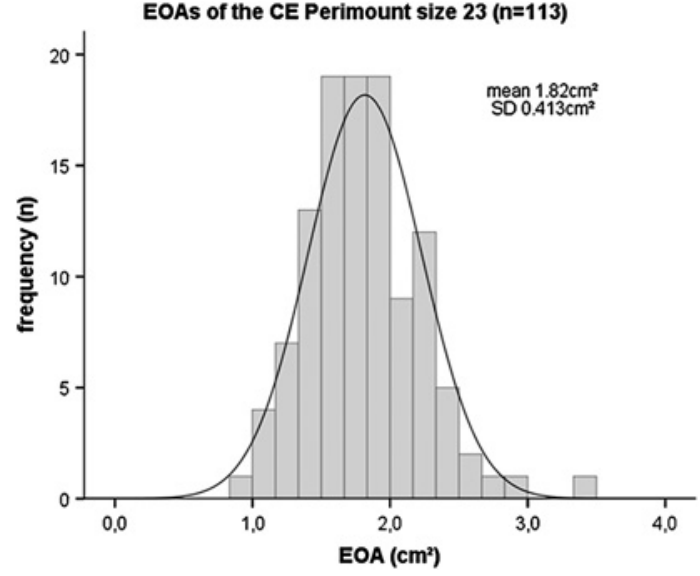

Figure 3 Effective orifice area index (EOAl) distribution. Histogram of the distribution of the EOAl among the patient population to demonstrate the continuous nature of the variable. The most commonly used thresholds for severe $\left(0.65 \mathrm{~cm}^{2} / \mathrm{m}^{2}\right)$ and moderate $\left(0.85 \mathrm{~cm}^{2} / \mathrm{m}^{2}\right)$ are drawn into the histogram.

again demonstrate that anticipating the EOA by reference tables instead of echo measurements would have led to $31.8 \%$ false assignments to PPM/no PPM groups, although this method is assumed to be better than using geometric or in vitro orifice area. ${ }^{14} \mathrm{~A}$ major reason responsible for the difficulty in accurate estimation of EOA is the broad interindividual variety of EOA even when patients are implanted with the same size and type of prosthesis (figure 1). This phenomenon is attributed to patient-specific differences in anatomical features of the aortic root (eg, larger or narrow sinuses of Valsalva) and patient haemodynamics, which are responsible for the significant difference in the opening and closing dynamics of individual prostheses. ${ }^{16} 17$

Currently, the majority of studies analysing the impact of PPM on clinical outcome are based on anticipations of PPM. The determination of EOA using reference tables is a valuable tool, particularly for intraoperative prediction of whether a patient is at risk of PPM. Such manoeuvres allowed us to significantly reduce the incidence of PPM. ${ }^{14}$ However, the validity of using reference values, which do not account for individual EOA variance, to determine the impact of PPM on morbidity or mortality after AVR, is a subject for discussion. On the other hand, the Doppler-echocardiographic measurement may be influenced by several factors that are not necessarily related to PPM itself, including patient's flow conditions during the echocardiographic measurement, subvalvular acceleration, or measurement errors such as underestimation of LVOT diameter or misalignment of the Doppler beam with transprosthetic flow jet. In addition, immediate postoperative measurements are less likely to be representative as haemodynamics are not well stabilised at such early time points. Patients investigated early

Table 3 Final prognostic model

\begin{tabular}{lllll}
\hline Predictors for cardiac death & HR & $\begin{array}{l}\text { Lower limit } \\
\mathbf{9 5 \%} \text { CI }\end{array}$ & $\begin{array}{l}\text { Upper limit } \\
\mathbf{9 5 \%} \text { CI }\end{array}$ & p Value \\
\hline Logarithmic EOAI & 0.32 & 0.12 & 0.85 & 0.022 \\
Age & 1.11 & 1.04 & 1.2 & 0.003 \\
Diabetes mellitus & 2.72 & 1.19 & 6.22 & 0.020 \\
Preoperative ejection fraction $<50 \%$ & 2.3 & 0.99 & 5.33 & 0.052 \\
\hline EOAl effective orifice area index & & & &
\end{tabular}

EOAl, effective orifice area index. 
Table 4 Final prognostic model for non-obese patients

\begin{tabular}{lllll}
\hline Predictors for cardiac death & HR & $\begin{array}{l}\text { Lower limit } \\
\mathbf{9 5} \mathbf{~ C l}\end{array}$ & $\begin{array}{l}\text { Upper limit } \\
\mathbf{9 5 \%} \mathbf{~ C l}\end{array}$ & p Value \\
\hline Logarithmic EOAI & 0.31 & 0.11 & 0.84 & 0.021 \\
Age & 1.11 & 1.03 & 1.19 & 0.007 \\
Diabetes mellitus & 3.71 & 1.45 & 6.95 & 0.010 \\
Preoperative ejection fraction $<50 \%$ & 1.63 & 0.65 & 4.11 & 0.300 \\
\hline
\end{tabular}

EOAl, effective orifice area index.

after AVR are more likely to be in a hyperdynamic state, or exhibit tachycardia, which makes assessment of the EOA difficult. Finally, the acoustic window is often of poor quality in the early postoperative period. To exclude the limitations of early postoperative measurements, we used the EAO measurements obtained at a follow-up investigation 6 months after AVR, which we consider representative and reproducible. We assume that errors up to $1 \mathrm{~cm}^{2}$ that may occur with the use of the mean values, as demonstrated in figure 1, are unlikely to result with the individual echocardiographic assessment of the EOA. Therefore, our group considered the echo measurements the most accurate method to assess the impact of the EOAI on midterm cardiac-related mortality.

To our knowledge, our study is the largest evaluation of PPM on survival using individual EOAI measurements. Two previous studies identifying PPM as an independent predictor for longterm mortality obtained echocardiographic data at a median follow-up of 6 days, ${ }^{18}$ or before discharge. ${ }^{19}$ According to the arguments stated above, we question the usefulness of such early postoperative echocardiographic measurements for characterisation of prosthesis function.

\section{Application of categorised EOAI for survival analysis}

Using the EOAI as a categorised variable, our data demonstrate a remarkably increased cumulative incidence of cardiac death in patients with PPM (EOAI $\left.\leq 0.85 \mathrm{~cm}^{2} / \mathrm{m}^{2}\right)$ (figure 2). The incidence of non-cardiac death was similar with or without PPM. The findings were not statistically significant at the 5\% level, either in the whole cohort or in the subgroups of non-obese patients and patients with a residual LVH. The EOAI is conventionally converted into categories by assigning patients into two groups ('no PPM', 'PPM'), ${ }^{20-25}$ three groups ('mild', 'moderate', 'severe PPM'), ${ }^{5-9} 18$ or more groups. ${ }^{19}$ This is partly driven by predetermination of cut-off values that will provide a significant association between PPM and outcome. This practice may contribute to undesirable statistical consequences like loss of efficiency, biased effect sizes and artificially low $p$ values. ${ }^{26}$ Current thresholds for severe and moderate PPM are in the range $0.6-0.65 \mathrm{~cm}^{2} / \mathrm{m}^{2}$ and $0.75-0.90 \mathrm{~cm}^{2} / \mathrm{m}^{2}$, further complicating the comparability of studies. To allow for better comparison of different studies, it will be essential to standardise the cut-off values. This study used the most common threshold of $0.85 \mathrm{~cm}^{2} / \mathrm{m}^{2}$

\section{Application of the continuous EOAI for survival analysis}

The key method of this study was to incorporate the EOAI as a continuous variable. The final multivariate model demonstrated a significantly increased risk for cardiac death with smaller EOAI with a hazard ratio of 0.32 in 622 patients who had
Figure 4 Influence of effective orifice area index (EOAl) on mortality risk. The risk plots indicate the cumulative incidence for cardiac death after 2, 3, 4 and 5 years in relation to EOAI. As indicated by the hazard ratio of 0.32 for EOAl, the risk of cardiac death after 2, 3, 4 or 5 years decreases with increasing EOAl for all demonstrated patient profiles while the slope of the curves increases with time. Upper left: effect of EOAI on overall survival after 2, 3, 4 and 5 years after operation for a 72-year-old patient with no diabetes and an ejection fraction (EF) $>50 \%$. Upper right: impact of EOAI on overall survival for an identical patient but with diabetes. As the hazard ratio of 2.72 for diabetes increases the risk of death, there is a higher mortality risk in relation to EOAI than for the patient with no diabetes. Bottom left: Additional low EF further increases the mortality risks after 2,3,4 and 5 years compared with the previous patient profiles (hazard ratio $(\mathrm{HR})=2.3$ ). Bottom right: this patient profile shows the risk for an 82-year-old patient with impaired EF and diabetes. As age increases the risk of death ( $H R=1.11)$, this patient shows the highest risks of death after 2,3,4 and 5 years compared with the other three patient profiles, exhibiting a steeper decrease of mortality risk with increasing EOAI than for the other patient profiles.
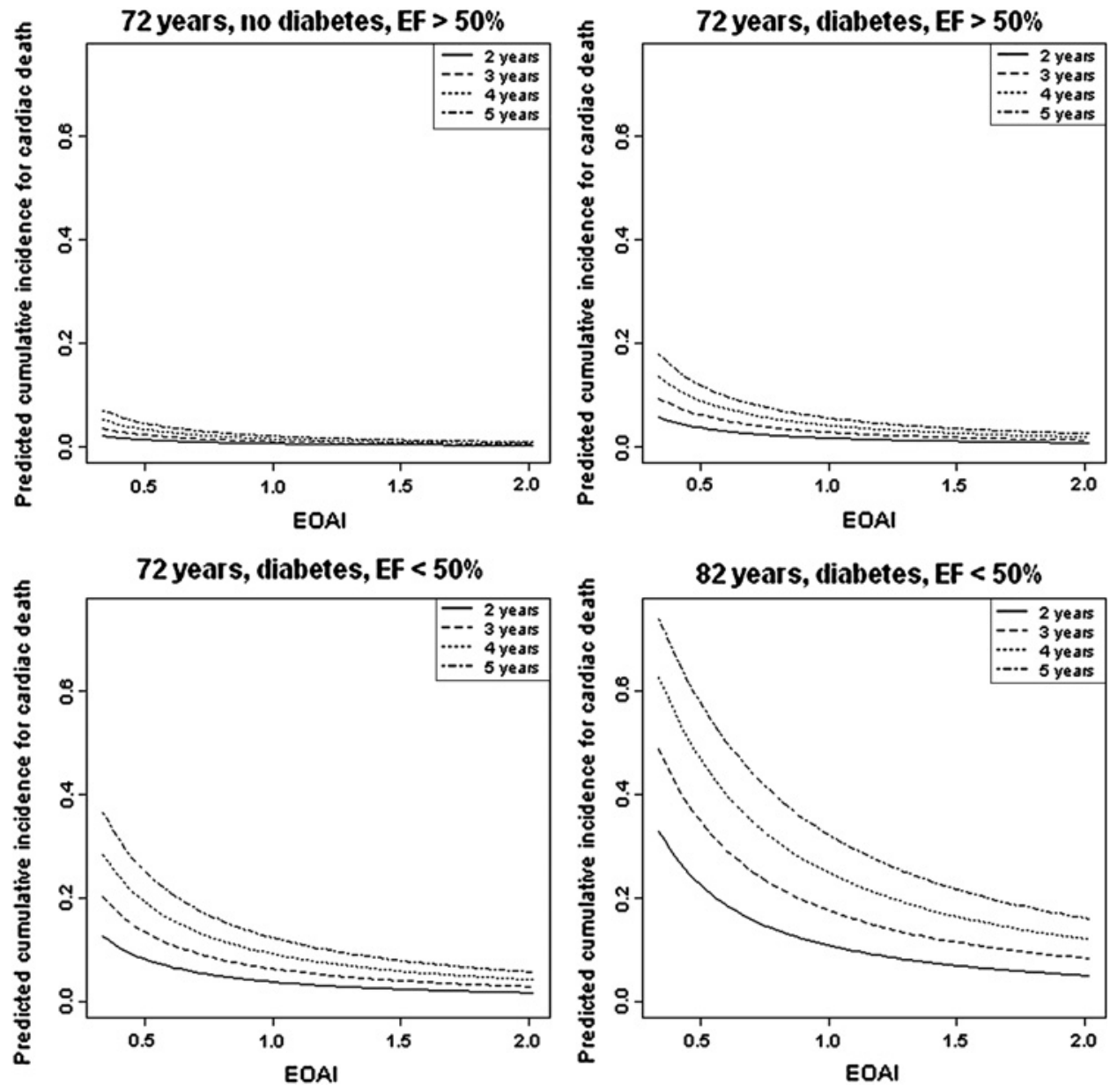
undergone AVR (table 3), while the descriptive analysis using categorised EOAI did not reach statistical significance. Earlier studies by Blackstone did model the indexed orifice area as a continuous variable, ${ }^{27-29}$ but used the geometric valve area to determine the presence of PPM. This variable was later proved to be unrelated to postoperative gradients and clinical outcomes. ${ }^{2}$ Risk plots for defined patient profiles additionally demonstrated a timedependent effect, as the slope of the curves for mortality risk increased between 2 and 5 years (figure 4). This finding shows that the negative impact of a smaller EOAI on outcome becomes increasingly apparent over time, possibly owing to the failure of left ventricular remodelling over time due to a residual degree of aortic stenosis. Long-term investigations have demonstrated a significant divergence of survival curves after 5 years, suggesting that the effect of PPM might become increasingly influential beyond the 5 -year follow-up that was provided in this study. ${ }^{9} 183031$ As survival after AVR is certainly affected by multiple factors, we found, furthermore, a significant influence of patient age, diabetes and impaired left ventricular function. The impact of these variables is well recognised in the published literature. $\begin{aligned} & 59 \\ & 9\end{aligned} 212329$ Finally, as survival after surgical AVR is usually excellent, and the number of events is low, adequate proof of an additional effect of PPM or the EOAI on survival largely depends on most accurate methodology, which includes respecting the continuous nature of the EOAI.

\section{Obesity and left ventricular mass}

In concordance with a previous study by Mohty et $a^{30}$ the effect of EOAI on survival was only significant in the non-obese patients with a BMI $<30 \mathrm{~kg} / \mathrm{m}^{2}$. In patients with a BMI $\geq 30 \mathrm{~kg} / \mathrm{m}^{2}$, the EOA indexed to the body surface area seems to be an inadequate tool for estimating PPM.

An impaired LVM regression generated by higher gradients is assumed to be the main deleterious effect of PPM. ${ }^{22}$ Our data showed an increased proportion of patients with a residual $\mathrm{LVH}$ of $>125 \mathrm{~g} / \mathrm{m}^{2}$ when the EOAI was $<0.85 \mathrm{~cm}^{2} / \mathrm{m}^{2}$. Furthermore, the cumulative incidence of cardiac death was strongly increased in patients with residual LVH and PPM (figure 2, NS). LVM regression depends on multiple factors, such as initial LVM, ${ }^{32}$ but PPM remains a factor that can be avoided by the surgeon.

\section{CONCLUSIONS}

In summary, our aim was to use improved methodology to evaluate the impact of PPM on survival after AVR. This was undertaken using echocardiographically determined EOA measurements and avoiding analysis of EOAI as a categorical variable. Our data demonstrate a clinically relevant, significant impact of smaller EOAIs on cardiac mortality after AVR, particularly in non-obese patients. Survival is certainly influenced by multiple factors, but PPM remains a factor that can be avoided by the surgeon. Therefore, we conclude that our data add important evidence that preventive strategies to avoid PPM during AVR are reasonable. Such strategies may include intraoperative anticipation of the EOA by reference tables, implantation of third-generation prostheses with larger EOAs or annular enlargement in selected patients. Taking into account our previous findings of impaired exercise capacity in patients with PPM, ${ }^{33}$ annular enlargement, in particular, may be advantageous for younger patients in whom PPM is predicted.

Further examinations of the effect of PPM on long-term mortality or morbidity should preferably use echocardiographic EOA measurements rather than estimations from reference tables. This would be helpful in avoiding inaccurate determi- nations of the presence or absence of PPM. Avoidance of dichotomisation or categorisation of the EOAI into groups is likely to further improve the statistical accuracy of follow-up studies. However, if categorisation is performed, authors should strive to use the same thresholds, for example, $0.65 \mathrm{~cm}^{2} / \mathrm{m}^{2}$ and $0.85 \mathrm{~cm}^{2} / \mathrm{m}^{2}$ as proposed by Pibarot and Dumesnil ${ }^{2}$ and which are also in concordance with the guidelines for the grading of native aortic valve stenosis. ${ }^{34}$

\section{Limitations}

Only patients who had 6 months' follow-up echocardiography at our institution were included in the study. Therefore, operative and short-term mortality was not investigated. This might have created a survival bias as several patients with severe PPM may have died before 6 months. LVM regression could not be included in this study, as there were no preoperative measurements. The data of LVM were complete in only $90 \%$ of the patients. As the number of events ( 25 cardiac deaths) was small, it will be necessary to increase the length of the follow-up of our patient group. The EOA was indexed to patients' body surface area, thus there might be a rationale for using other variables such as fat-free body mass.

\section{Competing interests None.}

Ethics approval This study was conducted with the approval of the local ethics committee (Technical University Munich, Germany).

Provenance and peer review Not commissioned; externally peer reviewed.

\section{REFERENCES}

1. Rahimtoola SH. The problem of valve prosthesis-patient mismatch. Circulation 1978;58:20-4.

2. Pibarot P, Dumesnil JG. Prosthesis-patient mismatch: definition, clinical impact, and prevention. Heart 2006;92:1022-9.

3. Richards KL. Assessment of aortic and pulmonic stenosis by echocardiography. Circulation 1991;84:1182-7.

4. DuBois D, DuBois EF. A formula to estimate the approximate surface area if height and weight be known. Arch Intern Med 1916;17:863-71.

5. Blais C, Dumesnil JG, Baillot R, et al. Impact of valve prosthesis-patient mismatch on short-term mortality after aortic valve replacement. Circulation 2003;108:983-88.

6. Flameng $\mathbf{W}$, Meuris $B$, Herijgers $P$, et al. Prosthesis-patient mismatch is not clinically relevant in aortic valve replacement using the Carpentier-Edwards Perimount valve. Ann Thorac Surg 2006;82:530-6.

7. Fuster RG, Montero Argudo JA, et al. Patient-prosthesis mismatch in aortic valve replacement: really tolerable? Eur J Cardiothorac Surg 2005;27:441-9.

8. Pibarot $\mathbf{P}$, Dumesnil JG. Hemodynamic and clinical impact of prosthesis-patient mismatch in the aortic valve position and its prevention. J Am Coll Cardiol 2000;36:1131-41.

9. Walther $\mathbf{T}$, Rastan A, Falk V, et al. Patient prosthesis mismatch affects short- and long-term outcomes after aortic valve replacement. Eur J Cardiothorac Surg 2006;30:15-9.

10. Devereux RB, Lutas EM, Casale PN, et al. Standardization of M-mode echocardiographic left ventricular anatomic measurements. J Am Coll Cardiol 1984; 4:1222-30.

11. Hirschl M. Linksventrikelhypertrophie. Journal für Kardiologie - Austrian Journal of Cardiology 2000; 7:489-91.

12. Gray RJ. A class of K-sample tests for comparing the cumulative incidence of a competing risk. Ann Stat 1988;16:1141-54.

13. Fine JP, Gray RJ. A proportional hazards model for the subdistribution of a competing risk. J Am Stat Assoc 1999;94:496-509.

14. Bleiziffer S, Eichinger WB, Hettich I, et al. Prediction of valve prosthesis-patient mismatch prior to aortic valve replacement: which is the best method? Heart 2007:93:615-20.

15. Altman DG, Lausen B, Sauerbrei W, et al. Dangers of using optimal cutpoints in the evaluation of prognostic factors. J Natl Cancer Inst 1994;86:829-35.

16. Guenzinger R, Eichinger WB, Hettich I, et al. A prospective randomized comparison of the Medtronic Advantage Supra and St Jude Medical Regent mechanical heart valves in the aortic position: is there an additional benefit of supra-annular valve positioning? J Thorac Cardiovasc Surg 2008;136:462-71.

17. Wagner IM, Eichinger WB, Bleiziffer S, et al. Influence of completely supra-annula placement of bioprostheses on exercise hemodynamics in patients with a small aortic annulus. J Thorac Cardiovasc Surg 2007;133:1234-41.

18. Mohty-Echahidi D, Malouf JF, Girard SE, et al. Impact of prosthesis-patient mismatch on long-term survival in patients with small St Jude Medical mechanical prostheses in the aortic position. Circulation 2006;113:420-6. 
19. Florath I. Impact of valve prosthesis-patient mismatch estimated by echocardiographic-determined effective orifice area on long-term outcome after aortic valve replacement. Am Heart J 2008;155:1135-42.

20. Howell NJ, Keogh BE, Barnet V, et al. Patient-prosthesis mismatch does not affect survival following aortic valve replacement. Eur J Cardiothorac Surg 2006;30:10-4.

21. Rao V, Jamieson WR, Ivanov J, et al. Prosthesis-patient mismatch affects survival after aortic valve replacement. Circulation 2000;102:III5-9.

22. Tasca G, Brunelli F, Cirillo M, et al. Impact of valve prosthesis-patient mismatch on left ventricular mass regression following aortic valve replacement. Ann Thorac Surg 2005; 79:505-10.

23. Ruel M, Al-Faleh $\mathrm{H}$, Kulik $\mathrm{A}$, et al. Prosthesis-patient mismatch after aortic valve replacement predominantly affects patients with preexisting left ventricular dysfunction: effect on survival, freedom from heart failure, and left ventricular mass regression. J Thorac Cardiovasc Surg 2006;131:1036-44.

24. Roscitano A, Benedetto U, Sciangula A, et al. Indexed effective orifice area after mechanical aortic valve replacement does not affect left ventricular mass regression in elderly. Eur J Cardiothorac Surg 2006;29:139-43.

25. Hanayama N, Christakis GT, Mallidi HR, et al. Patient prosthesis mismatch is rare after aortic valve replacement: valve size may be irrelevant. Ann Thorac Surg 2002;73:1822-9.

26. Sauerbrei W, Royston P, Binder H. Selection of important variables and determination of functional form for continuous predictors in multivariable model building. Stat Med 2007;26:5512-28.

27. Blackstone EH, Cosgrove DM, Jamieson WR, etal. Prosthesis size and long-term survival after aortic valve replacement. J Thorac Cardiovasc Surg 2003:126:783-96.
28. Koch CG, Khandwala F, Estafanous FG, et al. Impact of prosthesis-patient size on functional recovery after aortic valve replacement. Circulation 2005; 111:3221-9.

29. Medalion B, Blackstone EH, Lytle BW, et al. Aortic valve replacement: Is valve size important? J Thorac Cardiovasc Surg 2000;119:963-74.

30. Mohty D, Dumesnil JG, Echahidi N, et al. Impact of prosthesis-patient mismatch on long-term survival after aortic valve replacement: influence of age, obesity, and left ventricular dysfunction. J Am Coll Cardiol 2009;53:39-47.

31. Kohsaka S, Mohan S, Virani S, et al. Prosthesis-patient mismatch affects long-term survival after mechanical valve replacement. J Thorac Cardiovasc Surg 2008; 135:1076-80

32. Villa $\mathbf{E}$, Troise $\mathrm{G}$, Cirillo $\mathrm{M}$, et al. Factors affecting left ventricular remodeling after valve replacement for aortic stenosis. An overview. Cardiovasc Ultrasound 2006; $: 25$

33. Bleiziffer S, Eichinger WB, Hettich I, et al. Impact of prosthesis-patient mismatch on exercise capacity in patients after bioprosthetic aortic valve replacement. Heart 2008;94:637-41.

34. Bonow RO, Carabello BA, Kanu C, et al. ACC/AHA 2006 guidelines for the management of patients with valvular heart disease: a report of the American College of Cardiology/American Heart Association Task Force on Practice Guidelines (writing committee to revise the 1998 Guidelines for the Management of Patients With Valvular Heart Disease): developed in collaboration with the Society of Cardiovascular Anesthesiologists: endorsed by the Society for Cardiovascular Angiography and Interventions and the Society of Thoracic Surgeons. Circulation 2006;114:e84-231. 


\section{Heart}

\section{Impact of the indexed effective orifice area on mid-term cardiac-related mortality after aortic valve replacement}

Sabine Bleiziffer, Ayyaz Ali, Ina M Hettich, et al.

Heart 2010 96: 865-871 originally published online April 20, 2010 doi: 10.1136/hrt.2009.177220

Updated information and services can be found at:

http://heart.bmj.com/content/96/11/865.full.html

These include:

References This article cites 34 articles, 13 of which can be accessed free at: http://heart.bmj.com/content/96/11/865.full.html\#ref-list-1

Article cited in:

http://heart.bmj.com/content/96/11/865.full.html\#related-urls

Email alerting Receive free email alerts when new articles cite this article. Sign up in service the box at the top right corner of the online article.

Topic Articles on similar topics can be found in the following collections Collections

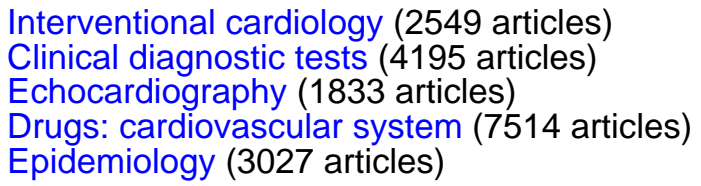

Notes

To request permissions go to:

http://group.bmj.com/group/rights-licensing/permissions

To order reprints go to:

http://journals.bmj.com/cgi/reprintform

To subscribe to BMJ go to:

http://group.bmj.com/subscribe/ 